Available online at www.sciencedirect.com

Research Paper

\title{
Hierarchical structures of $\beta$-TCP/45S5 bioglass hybrid scaffolds prepared by gelcasting
}

\author{
João Henrique Lopes ${ }^{a, *, 1}$, Jéssica Aparecida Magalhães ${ }^{b}$, \\ Rubia Figueredo Gouveia ${ }^{c}$, Celso Aparecido Bertran ${ }^{a}$, Mariana Motisuke ${ }^{b}$, \\ Samira E. A. Camargo ${ }^{d}$, Eliandra de Sousa Trichês ${ }^{b, 1}$
}

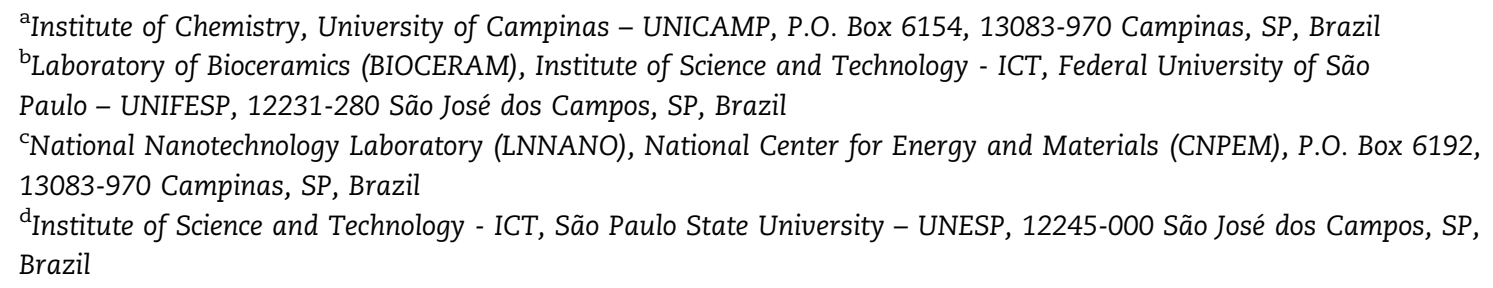

\section{A R T I C L E I N F O}

\section{Article history:}

Received 20 February 2016

Received in revised form

20 April 2016

Accepted 22 April 2016

Available online 28 April 2016

\section{Keywords:}

$\beta$-TCP

45S5 bioglass

Scaffolds

Gelcasting

Bioactivity

\section{A B S T R A C T}

This paper investigates the microstructure and the mechanical properties of $\beta$ tricalcium phosphate ( $\beta$-TCP) three-dimensional (3D) porous materials reinforced with $45 \mathrm{~S} 5$ bioactive glass (BG). $\beta$-TCP and $\beta$-TCP/x\%-BG scaffolds with interconnected pores networks, suitable for bone regeneration, were fabricated by gel-casting method. Mechanical properties, porosity, and morphological characteristics were evaluated by compressive strength test, scanning electron microscopy (SEM) and X-ray microtomography analysis, whereas the structures were fully explored by XRD, and Raman spectroscopy. To the best of our knowledge, this is the first time where the mechanism for understanding the effect of bioglass on the mechanical properties and microstruture of $\beta$-TCP/45S5-BG scaffolds has been systematically studied. The findings showed that ionic product lixiviated from $45 S 5$ bioactive glass, rich in silicon species and sodium ion, catalyzes a phase transition from $\beta$-TCP to Si-TCP by replacement of phosphorus for silicon and contributes to the improvement of scaffolds mechanical properties. The compressive strength of $\beta-\mathrm{TCP} / 5 \%-\mathrm{BG}$ and $\beta-\mathrm{TCP} / 7.5 \%-\mathrm{BG}$ was improved around $200 \%$ in comparison to pure $\beta$-TCP. Osteoblast-like cells (MG 63) were exposed to the materials for $24 \mathrm{~h}$ through the use of medium conditioned by $\beta$ tricalcium phosphate/bioactive glass. Cell viability was measured by MTT assay in the cells and the data obtained were submitted to ANOVA, Tukey's multiple comparison

\footnotetext{
*Corresponding author: Institute of Chemistry, University of Campinas - UNICAMP, P.O. Box 6154, 13083-970, Campinas, SP, Brazil. Tel.: +55 (19) 35213036

E-mail addresses: henriquelopez@gmail.com (J.H. Lopes), jessica.magalhaes@unifesp.br (J.A. Magalhães), rubia.gouveia@lnnano.cnpem.br (.F. Gouveia), bertran@iqm.unicamp.br (C.A. Bertran), motisuke@unifesp.br (M. Motisuke), samira@fosjc.unesp.br (S.E. A. Camargo), eliandra.sousa@unifesp.br (E.d.S. Trichês).

${ }^{1}$ These authors contributed equally.
} 
$(p<0.05)$. The $\beta$-TCP/7.5-BG promoted an increase of cell proliferation. The results suggest that compositions and processing method studied may provide appropriate materials for tissue engineering.

(c) 2016 Elsevier Ltd. All rights reserved.

\section{Introduction}

Bone tissue engineering features an alternative approach for regenerating and repairing damaged bone tissues owing to injuries and osteochondral lesions, tumor removal, or more commonly, age-related diseases such as osteoporosis and osteoarthritis (Fisher and Mauck, 2013; Naderi et al., 2011). Scaffolds derived from bioceramics have been successfully employed for bone repair and re-construction of diseased or damaged parts in dental and orthopedics applications (Baino and Vitale-Brovarone, 2011; Gerhardt and Boccaccini, 2010; Wu et al., 2011; Zhang et al., 2012).

Among bioceramics, $\beta$-tricalcium phosphate $(\beta$-TCP) and hydroxyapatite (HA) are the two commonly investigated for biomedical purpose and for scaffold construction in bone tissue engineering (Yang et al., 2015; Shavandi et al., 2015; Serra et al., 2015). Although, $\beta$-TCP and HA have both biocompatible and osteoconductive properties, the $\beta$-TCP is far more reabsorbable, indicating that it may interact with the hard tissues. This important feature makes $\beta$-TCP an interesting material for the manufacture of temporary scaffold that degrades with advancing bone growth, thus allowing bone to regenerate (Hesaraki et al., 2009; Li et al., 2011; Liang et al., 2010; Reid et al., 2005). Although, $\beta$-TCP presents two main disadvantages: the absence of osteostimulation properties and its brittleness under loading, which is a common feature in all bioceramic materials (Debusscher et al., 2009).

Some approaches may circumvent these disadvantages such as the addition of a second phase, which may introduce or enhance some properties of interest, such as mechanical strengthening and bioactivity. Recent works highlighted the potential of bioactive glasses for strengthening calcium phosphate ceramics besides of the ability to induce rapid response in terms of bone healing (Shuai et al., 2014; Langstaff et al., 2001; Salih et al., 2001). However, all these papers have merely discussed the effects of combining calcium phosphates and bioglass on the final properties of the composite rather than address the discussions for the mechanisms by which it occurs.

Several methods have been developed for processing three-dimensional (3D) scaffolds (Deville et al., 2006; Lin et al., 2008; Kim et al., 2009; Chopra et al., 2012; Yang et al., 2010). Evidently, each of these techniques in spite of its advantages will have inherent drawbacks, and cannot fully satisfy some characteristics required for an ideal scaffold, for example, suitable mechanical strength, controlled total porosity and pore sizes, and well-defined pore connectivity (Yang et al., 2010).

Among all processing routes for fabricating bioceramic scaffolds, gel-casting of foams is an interesting technique to prepare scaffolds with relatively large-sized pores, high mechanical strength (Chopra et al., 2012; Yang et al., 2010), reasonable interconnected pore channels and, mainly, by its ability for mass reproduction (Wu et al., 2011).

In this work, synergic and complementary approach by combining the biocompatibility, osteoconductivity and osteointegration of $\beta$-TCP with the osteogenic properties of $45 \mathrm{~S} 5$ bioactive glass (BG) for scaffolds obtained by gel-casting were developed. Furthermore, osteoblast-stimulating bioactive glass properties associated with gene up-regulation and microstructural aspects were addressed aiming to prepare scaffolds with enough mechanical strength to provide structural support for bone tissue engineering. Mechanical properties, porosity, and morphological characteristics were evaluated by compressive strength tests, scanning electron microscopy (SEM) and X-ray microtomography analysis, whereas the structural aspects were fully explored by XRD, and Raman spectroscopy and solid-state magic-angle spinning (Elliott, 1994) P MAS NMR spectroscopy. To the best of our knowledge, this is the first time the mechanism for understanding the bioglass effect on the mechanical properties and microstruture of $\beta$-TCP/45S5-BG scaffolds has been systematically studied. In addition, in vitro study was performed, where the cell viability was measured by MTT assay on an established lineage of osteoblast-like cells (MG 63).

\section{Experimental details}

\subsection{Preparation and characterization of $\beta$-TCP and 4555 bioglass powders}

$\beta$-TCP powder was synthesized via solid-state reaction as described elsewhere (Oliveira et al., 2008; Reno et al., 2014). Briefly, a 2:1 molar ratio mixture of $\mathrm{CaHPO}_{4}$ (Synth, Brazil) and $\mathrm{CaCO}_{3}$ (Synth, Brazil) was calcined at $1050{ }^{\circ} \mathrm{C}$ (EDG Inox Line/3000 3P/1200 ${ }^{\circ} \mathrm{C}$, SP, Brazil) followed by milling in a horizontal ball mill (MA500, Marconi, Piracicaba, SP, Brazil) during $48 \mathrm{~h}$ (alumina milling media of $6 \mathrm{~mm}$ of diameter and ball/powder weight ratio of 10:1). The resulting powder was analyzed by laser diffraction (Mastersizer 2000, Malvern) and presented a mean particle size of $3.42 \mu \mathrm{m}\left(D_{50}\right.$ value) and a particle size distribution between $0.78 \mu \mathrm{m}\left(D_{10}\right.$ value) and $25.2 \mu \mathrm{m}\left(D_{90}\right.$ value).

Bioglass $45 \mathrm{~S} 5$ (46.1 mol\% $\mathrm{SiO}_{2}$, $26.9 \mathrm{~mol} \% \mathrm{CaO}, 24.4 \mathrm{~mol} \%$ $\mathrm{Na}_{2} \mathrm{O}$, and $2.6 \mathrm{~mol} \% \mathrm{P}_{2} \mathrm{O}_{5}$ ) was prepared using a traditional melt-quenching technique (Lopes et al., 2014; Lopes et al., 2013). High purity $\mathrm{SiO}_{2}, \mathrm{Na}_{2} \mathrm{CO}_{3}, \mathrm{CaCO}_{3}$, and $\mathrm{P}_{2} \mathrm{O}_{5}$ powders (>99.9\%, Sigma-Aldrich, St. Louis, MO, USA) were mixed to obtain the $45 \mathrm{~S} 5$ bioglass composition. Thirty-gram batches were melted in platinum crucible at $1400^{\circ} \mathrm{C}$ in air for $3 \mathrm{~h}$ using a furnace (Lindberg/Blue M $1700^{\circ} \mathrm{C}$, Thermo Electron 
Corporation, Asheville, NC, USA). At the end of the refining process, the melts were quenched in air by pouring it into a graphite mold, which were annealed at $500^{\circ} \mathrm{C}$ for relieving the thermal stresses during $12 \mathrm{~h}$ in air before being slowly cooled to room temperature. The glass block was crushed and reduced to powder with particle sizes below $40 \mu \mathrm{m}$, and then milled in a horizontal ball mill (MA500, Marconi, Piracicaba, $\mathrm{SP}$, Brazil) for $48 \mathrm{~h}$ (alumina milling media of $10 \mathrm{~mm}$ of diameter and ball/powder ratio of 10:1). Finally, 45S5 bioglass powder was analyzed by laser diffraction (CILAS 1190L, Madison, WI, USA) and presented a mean particle size of was $6.02 \mu \mathrm{m}$ ( $D_{50}$ value) and a particle size distribution ranging from $0.19\left(D_{10}\right.$ value) to $17.34 \mu \mathrm{m}$ ( $D_{90}$ value).

\subsection{Fabrication of 3D scaffolds by gelcasting method}

The $\beta$-TCP and $\beta$-TCP/45S5-BG scaffolds were fabricated by gel-casting method (Wu et al., 2011; Ortega et al., 2003). Ceramic slurries with solid load of 35 vol\% were prepared by dispersing the $\beta$-TCP powder in aqueous solution containing 15 vol\% of organic monomers (methacrylamide-MAM, N,N, $\mathrm{N}^{\prime}$, $\mathrm{N}^{\prime}$-hydroxymethyl acrylamide-HMAM, and methylenebisacrylamide-MBAM) at a molar ratio of 3:3:1 (MAM:HAMAM: MBAM). All organic monomers were purchased from SigmaAldrich (Sigma-Aldrich, St. Louis, MO, USA). Ammonium polymethacrylate (Darvan ${ }^{\text {CO }}$ C-N, R.T. Vanderbilt Company, Inc., Norwalk, CT, USA) was used as dispersing agent. The slurry was homogenized in a horizontal ball mill (MA500, Marconi, Piracicaba, SP, Brazil) for $15 \mathrm{~min}$. In a further step, the catalyst for the gelation reaction $\mathrm{N}, \mathrm{N}, \mathrm{N}, \mathrm{N}^{\prime}$-tetramethylethylenediamine (TEMED) (Sigma-Aldrich, St. Louis, MO, USA), the initiator ammonium persulfate (APS, Vetec, Duque de Caxias, RJ, Brazil), and the non-ionic surfactant (Lutensol ON-110, BASF, Ludwigshafen, Germany) were added to the slurry. The mixture was vigorously stirred and foamed for 2 min using a standard mixer.

The foam obtained was dried and aged at $50^{\circ} \mathrm{C}$ for $24 \mathrm{~h}$ in an oven (MA035/1 Marconi, Piracicaba, SP, Brazil). The samples were obtained from green bodies (rigid foam) using a core drilling machine (diameter $x$ height, $7 \times 14 \mathrm{~mm}$ ) and sintered in air at a high temperature using a furnace (Lindberg/Blue $\mathrm{M} 1700^{\circ} \mathrm{C}$, Thermo Electron Corporation, Asheville, NC, USA). The heat treatment was performed as follow: (i) organic burn out was made with a heating rate of $1{ }^{\circ} \mathrm{C} \cdot \mathrm{min}^{-1}$ up to $500^{\circ} \mathrm{C}$ and dwell time of $1 \mathrm{~h}$; (ii) sinterization was carried out at $1200^{\circ} \mathrm{C}$ with a heating rate of $5^{\circ} \mathrm{C}$ $\min ^{-1}$ and dwell time of $2 \mathrm{~h}$. Samples were cooled down to room temperature inside the furnace.

In order to evaluate the effect of surfactant concentration on the scaffold porosity, porous morphology, and compressive strength, mixtures containing different amount of surfactant in the range of $0.12-0.70 \%$ were prepared.

The procedure aforementioned was also used to prepare the $\beta$-TCP/BG scaffolds, where the $45 \mathrm{~S} 5$ bioglass powder was added to the ceramic slurry at 5, and $7.5 \mathrm{wt} \%$ (related to wt\% of $\beta$-TCP in the slurry).

\subsection{Structural and morphological characterization of $\beta$ - TCP and $\beta$-TCP/45S5 bioglass scaffolds}

Crystallinity was analyzed by X-ray powder diffraction (XRD) using a diffractometer (XRD-7000, Shimadzu Scientific Instruments, Tokyo, Japan) with a Bragg Brentano camera geometry, $\mathrm{Cu}-\mathrm{K}_{\alpha}$ incident radiation $(\lambda=1.5418 \mathrm{~A}), 40 \mathrm{kV}, 30 \mathrm{~mA}$ and acquisition rate of $2^{\circ} \mathrm{min}^{-1}$ between $10-60^{\circ}(2 \theta)$ range. Raman spectra were recorded by using a triple spectrometer Raman system (T-64000, HORIBA Jobin Yvon S.A.S., Longjumeau, France) equipped with a detection system Charge Couple Device (CCD). Collection of the scattered light in the backscattering geometry was made using a confocal microscope $(\mathrm{B} \times 41$, Olympus optical Co. Ltd., Tokyo, Japan) with a $100 \times$ objective to collect the Raman signal, which in turn was spectrally analyzed with a spectrometer with a typical resolution of $2 \mathrm{~cm}^{-1}$. Raman spectra were recorded between 200 and $1300 \mathrm{~cm}^{-1}$, using the $532 \mathrm{~nm}$ exciting lines. The power of illumination was $10 \mathrm{~mW}$.

The scaffold surface morphology was investigated by scanning electron microscopy (FEI QUANTA FEG 250 ESEM, FEI Company, Hillsboro, Oregon, USA or 6360-Lev SEM, JEOL Ltd., Tokyo, Japan) with an energy-dispersive X-ray spectroscopy (EDS) analyzer (NORAN ${ }^{\mathrm{TM}}$ System 7 X-ray Microanalysis System, Thermo Fisher Scientific, Inc., Waltham, MA, USA). Samples were carbon coated using carbon thread on a sputter-coater (BALTEC Maschinenbau AG Med model 020, Pfaffikon, Switzerland) with a carbon evaporative attachment prior to elemental analysis, X-ray mapping, Secondary Electron (SE) and Backscattered Electron (BSE) imaging. Spectral Imaging by X-Ray Mapping technique was performed using a spatial resolution of $1024 \times 768$ pixels with a dwell time of $470 \mathrm{~ms}$, frame time of 500 and number of frame of 5 , resulting in an acquisition time of $2560 \mathrm{~min}$. The mapped region was selected using a magnification of 2000 times and electron beam energy of $15 \mathrm{kV}$ (accelerating voltage).

\subsection{Scaffolds' geometrical porosity}

Total porosity of scaffolds was obtained by Eq. 1 where " $d$ " is the geometrical density of the specimen, and $d_{\text {scaffolds }}$ is the theoretical density of the scaffolds that was calculated, for each formulation, by Eq. 2 (Xu et al., 2001, 2007). $d_{\beta-T C P}$ and $d_{B G}$ are the theoretical density of $\beta$-TCP $\left(3.07 \mathrm{~g} \mathrm{~cm}^{-3}\right)$ (Elliott, 1994) and bioglass $\left(2.72 \mathrm{~g} \mathrm{~cm}^{-3}\right.$ ) (Lopes et al., 2014), respectively. $X_{B G}$ and $X_{\beta-T C P}$ are the mass fraction of each phase added during scaffold fabrication.

$$
\begin{aligned}
& P=1-\left(\frac{d}{d_{\text {scaffolds }}}\right) \\
& d_{\text {scaffolds }}=\left[\left(d_{B G} x X_{B G}\right)+\left(d_{\beta-T C P} \times X_{\beta-T C P}\right)\right]
\end{aligned}
$$

\subsection{Compressive strength tests}

The compressive strength of the scaffolds was determined by using a universal testing machine (DL2000, EMIC, São José dos Pinhais, PR, Brazil). The compression tests were carried out at a crosshead speed of $0.5 \mathrm{~mm} \mathrm{~min}^{-1}$ and a load cell of $10 \mathrm{kN}$. 
Prior to the test, the samples were cut as plane-parallel as possible in order to avoid shear failure during testing. The scaffold cylindrical samples had a diameter of $7 \mathrm{~mm}$ and height of $14 \mathrm{~mm}$. At least, ten samples were tested and the mean strength and standard deviation were determined.

\subsection{Statistics}

One-way analysis of variances (ANOVA) has been performed by using a statistical software (Minitab ${ }^{\circledR}$ Software Version 14.1, Minitab Inc., Pennsylvania, USA) aiming to compare differences between the mean values of samples' compressive strength and total porosity using a confidence level of 95\%. Tukey's comparison post hoc test was performed to assess differences in each pair of means. Normality and equal variances tests were conducted prior to ANOVA to guarantee that data followed Normal distribution and presented homoscedasticity.

\subsection{X-ray microtomography}

X-ray microtomography images were obtained from $\beta$-TCP, $\beta$ $\mathrm{TCP} / 5 \% \mathrm{BG}$ and $\beta$-TCP/7.5\% BG scaffolds, using a high resolution X-ray microtomograph (SkyScan 1272 Bruker microCT, Kontich, Belgium). The X-ray source voltage and current used were $60 \mathrm{kV}$ and $166 \mu \mathrm{A}$, respectively. The nominal resolution was $6.5 \mu \mathrm{m}$ using the X-ray detector of $1224 \times 820$ pixels. NRecon software (Software Version 1.6.9.8, Bruker MicroCT ${ }^{\mathbb{R}}$ ) was used to reconstruct cross-section images from microtomography projections to 3D images, using Feldkamp algorithm. The same electronic density contrast limits were selected for all samples, permitting comparisons. The 3D images visualizations were acquired in the CTVOX program (Software Version 2.7.0, Bruker MicroCT ${ }^{\mathbb{R}}$ ). The 2D images per slices were obtained by Dataviewer software (Software Version 1.5.1.2, Bruker MicroCT ${ }^{\circledR}$ ). The total porosity and pore size distribution, solid composition, number of objects and fragmentation indexes were quantified using the CT analyzer software (Software Version 1.14.4.1, Bruker MicroCT ${ }^{\mathbb{R}}$ ). For the acquisition of all quantitative porosity parameters the preset VOI (volume object of interest) was of $8 \mathrm{~mm}^{3}$.

\subsection{In vitro essays: cell culture}

In this study, osteoblast-like cells (MG 63) were obtained from the Rio de Janeiro Cell Bank (Rio de Janeiro, RJ, Brazil). The cells culture were cultured in DMEM (Cultilab Curitiba, Brazil) supplemented with $10 \%$ of fetal bovine serum (FBS), penicillin $\left(100 \mathrm{U} \mathrm{mL}^{-1}\right)$, and streptomycin $\left(100 \mathrm{mg} \mathrm{mL}^{-1}\right)$ and maintained at $37^{\circ} \mathrm{C}$ and $5 \%$ of $\mathrm{CO}_{2}$. Cell culture flasks of $75 \mathrm{~mL}$ and $250 \mathrm{~cm}^{2}$ were used. The culture medium was changed every two days and cell growth was assessed by using a reverse phase microscope (Microlimaging $\mathrm{GmbH}$-Axiovert 40C, Carl Zeiss Microscope, Jena, Germany).

The cell attachment and the morphology of the cells were investigated using SEM (Inspect S50, FEI Company, Brno, Tcheca Republik) after 3 days of MG 63 cells growth on the samples. The supernatants were removed and the samples were rinsed twice with PBS. The adhered cells in samples were fixed with $4 \%$ glutaraldehyde in PBS, dehydrated using a series of ascending ethanol concentrations (70\%, $80 \%, 90 \%$ and $100 \%$ at $20 \mathrm{~min}$ each) and air-dried at room temperature for $24 \mathrm{~h}$. For SEM examination, the samples were sputtercoated with palladium-gold alloy (Polaron SC 7620 Sputter Coater, Quorum Technologies, Newhaven, UK) at a thickness of 7-10 nm (10-15 mA, under a vacuum of $130 \mathrm{mTorr})$. The SEM was operated between 15 and $30 \mathrm{kV}$, spot 3-6.

For the cytotoxicity test, $8 \times 10^{3}$ cells were plated in 96 -well plates. Eight wells were used for each material and positive control $(n=12)$. The cells were maintained in DMEM supplemented with $10 \% \mathrm{FBS}$, penicillin $\left(100 \mathrm{U} \mathrm{mL}^{-1}\right)$ and streptomycin $\left(100 \mathrm{mg} \mathrm{mL}^{-1}\right)$ at $37^{\circ} \mathrm{C}$ for $24 \mathrm{~h}$ in a humidified atmosphere with $5 \% \mathrm{CO}_{2}$. The cell proliferation in contact with the samples was determined by using water soluble enzyme substrate 3-(4,5-dimethylthiazol-2-yl)-2,5-diphenyl tetrazolium bromide (MTT) (Sigma, St Louis, MO, USA). MTT is converted to blue water insoluble product formazan accumulated in the cytoplasm of viable cells (Hesaraki et al., 2009). The cell viability was quantified by dissolution of MTT in $0.1 \mathrm{~mol} \mathrm{~L}^{-1} \mathrm{NaOH}$ in DMSO (dimethyl sulfoxide) and the absorbance of the produced formazan was measured at $570 \mathrm{~nm}$ with a spectrophotometer (Biotek-EL808IU, BioTek Instruments, Inc., Winooski, VT, USA) at $570 \mathrm{~nm}$. The cytotoxicity was expressed as percentage relative to the control group (100\%).

\section{Results and discussion}

3.1. Effect of surfactant concentration on the total porosity, morphology and compressive strength of the scaffolds: optimization studies

The effect of surfactant concentration on the total porosity, morphology and compressive strength of scaffolds was assessed preliminary for pure $\beta$-TCP, aiming to optimize the gel-casting method. Toward this purpose, the following range of surfactant concentrations was investigated: $0.12-0.70 \mathrm{wt} \%$. SEM micrographs of the fracture surface of the $\beta$-TCP scaffolds prepared with different surfactant contents are presented in Fig. SM.1 (see topic SM.1). Table 1 shows the porosity and compressive strength values for $\beta$-TCP scaffolds prepared with different amounts of surfactant agent.

The effect of surfactant agent on the porosity is an important variable on the gel-casting method since the higher surfactant content, the higher the volume of foam formed during stirring and, consequently, the higher is the porosity generated after the system gelation. Indeed, the porosity of $\beta$-TCP scaffolds increases as the surfactant quantity increases (Table 1). The $\beta$-TCP scaffolds presented

Table 1 - Porosity and compressive strength values for $\beta$-TCP scaffolds prepared with different amounts of surfactant agent.

\begin{tabular}{lcl} 
Surfactant (wt\%) & Porosity (\%) & Compressive strength (MPa) \\
\hline 0.12 & $81.6 \pm 0.6$ & $0.9 \pm 0.3$ \\
0.23 & $83.6 \pm 0.8$ & $0.7 \pm 0.4$ \\
0.50 & $86 \pm 1$ & $0.3 \pm 0.2$ \\
0.70 & $89 \pm 1$ & $0.1 \pm 0.2$ \\
\hline
\end{tabular}


porosities in the range of $81.6-89 \%$, which is inside the porosity range of the trabecular bone (75-90\%) (Black and Hastings, 1998). ANOVA results revealed a $p$ value $\leq 0.05$ and Tukey's comparison test yield significant difference among the samples' total porosity.

To select an optimal relationship between surfactant content and compressive strength, ANOVA results and Tukey's comparison must be analyzed. ANOVA results for compressive strength of 0.9 and $0.1 \mathrm{MPa}$ and total porosity of $81.6 \%$ and $89 \%$ showed a $p=0$, however, Tukey's comparison revealed that there are only two groups of samples that are statistically different: $81.6-83.6 \%$ (0.12 and $0.23 \mathrm{wt} \%$ of surfactant) and $86-89 \%$ (0.50 and $0.70 \mathrm{wt} \%$ of surfactant). Based on these results the optimum group is $\beta$-TCP scaffolds with $83.6 \%$ porosity and $0.7 \mathrm{MPa}$, i.e. the highest porosity in the group with the highest compressive strength, corresponding to an optimal surfactant concentration of $0.23 \%$.

\section{2. $\quad \beta$-TCP and $\beta$-TCP $/ x \%$-BG scaffolds}

The geometrical porosity and compressive strength values for $\beta$-TCP and $\beta$-TCP/x\%-BG scaffolds foamed with $0.23 \%$ surfactant and sintered at $1200{ }^{\circ} \mathrm{C}$ for $2 \mathrm{~h}$ are summarized in Table 2.

Based on ANOVA $(p=0.49)$ and Tukey's comparison tests it is possible to ensure with $95 \%$ of certainty that the incorporation of different amounts of bioglass (5 and $7.5 \mathrm{wt} \%$ ) did not result in changes in the total porosity of the pure $\beta$-TCP scaffolds. On the other hand, the mechanical strength was substantially improved by the presence of bioglass (one-way ANOVA test retrieved a $p$ value $\leq 0.05$ ). $\beta$-TCP/x\%-BG scaffolds showed a mechanical strength approximately twice as high as compared to pure TCP. Tukey's comparison revealed that the compressive strength of scaffolds reinforced with BG is not statistically different, indicating that $5 \%$ of BG added is sufficient to improve the mechanical strength of the scaffolds. In addition, $\beta$-TCP/x\%-BG scaffolds showed values of porosity and mechanical strength near to the trabecular bone, between $75 \%$ and $85 \%$ porosity and 2-12 MPa for mechanical strength (Black and Hastings, 1998).

Although a significant improvement in mechanical properties has been achieved for $\beta$-TCP/x\%-BG scaffolds, such values are still low compared with those reported for sponge bone (Black and Hastings, 1998; Hench and Wilson, 1999). It has been speculated that the scaffold does not need to have a mechanical strength equal to spongy bone (2-12 MPa) because cultured cells on the scaffold and new tissue formation in vitro will create a biocomposite and will increase significantly the time-dependent strength of the scaffold (Jones and Hench, 2003a; Jones and Hench, 2003b).

Table 2 - Porosity and compressive strength values for $\beta$-TCP and $\beta$-TCP $/ x \%$-BG scaffolds foamed with $0.23 \%$ surfactant and sintered at $1200{ }^{\circ} \mathrm{C}$ for $2 \mathrm{~h}$.

\begin{tabular}{lll}
$\boldsymbol{\beta}$-TCP/x\%-BG & Porosity (\%) & Compressive strength (MPa) \\
\hline 0 & $83.6 \pm 0.8$ & $0.7 \pm 0.4$ \\
5 & $84.1 \pm 0.6$ & $1.5 \pm 0.6$ \\
7.5 & $83.4 \pm 0.4$ & $1.4 \pm 0.2$ \\
\hline
\end{tabular}

It is also worth noting that the processing route used for the preparation of scaffolds plays an important role in the microstructural properties of the material. As a result, scaffolds prepared starting from the same matrix, but using different experimental methods generally result in porous bodies with different mechanical behavior. Thus, any comparison between experimental results obtained with the published literature are useful for the scaffolds prepared using the same preparation method and that exhibit the same range of porosity. Sepulveda et al. (2000) reported the production of hydroxyapatite scaffolds exhibiting relative porosities varying within the boundaries of 0.724 and 0.899 and the compressive strength varied within the range 1.6$5.8 \mathrm{MPa}$. Wu et al. (2011) described the prepare of bioglass scaffolds exhibiting porosity of $79 \%$ and compressive strength of $1.9 \mathrm{MPa}$. In both cases, the values described for compressive strength to scaffolds with similar porosities are close to the values obtained in this work.

Fig. 1 shows the SEM micrographs of the surface of fracture of the $\beta$-TCP (Fig. 1(a-c)), $\beta$-TCP/5\%-BG (Fig. 1(d-f)), and $\beta$-TCP/7.5\%-BG (Fig. 1 (g-i)) scaffolds. All scaffolds presented a homogeneous morphology, revealing a uniform distribution of the spherical macropores interconnected with their neighbors (Fig. 1(a, d, and g)). The mean pore size, estimated from the SEM images, varied in the range of 200$500 \mu \mathrm{m}$, which is suitable to allow cell attachment, proliferation, and differentiation, and to provide pathways for biofluids. By increasing the micrographs magnification is possible to notice for $\beta$-TCP/5\%-BG (Fig. 1e) a microstructure more homogeneous in comparison with the pure $\beta$-TCP (Fig. 1b) or $\beta$-TCP/7,5\%-BG (Fig. 1h).

Differences in the degree of sintering of the scaffolds grains are unclear (Fig. 1(c, f, and i)), which suggests that improvements in mechanical properties in the studied samples are not associated with a structural densification. This absence of a structural compaction confirms that the bioglass plays an important role in increasing the intensity of adhesion strength between the grains that make up the walls of the scaffold. Thus, microstructural changes observed in the $\beta$ $\mathrm{TCP} / \mathrm{x} \%$-BG scaffolds can be credited to the all species (silicon, calcium, phosphorus, and sodium) leached from the bioglass during the gel-casting/ sintering of the scaffolds which alters the chemical composition of $\beta$-TCP surface grains. In particular, the sodium ion that is known as a fluxing agent (Brazing, 2003). The sodium may lead to a softening of the surface of the TCP granules at lower temperatures than those usually observed for the $\beta$-TCP pure, resulting in an increase in the intensity of bond strength between neighboring grains.

Another important feature related to the scaffold architecture is a wide distribution of pore size $(20-500 \mu \mathrm{m})$, which is an important factor for the effective scaffold vascularization and for bone ingrowth (Gerhardt and Boccaccini, 2010). The pore size distribution of the $\beta$-TCP and $\beta$-TCP/x\%-BG scaffolds measured by nitrogen adsorption porosimetry confirms the presence of a hierarchical structure for all prepared scaffolds (Fig. SM.2 - see topic SM.2). The presence of a bimodal porosity, interconnected porous structure (higher pores, $200-500 \mu \mathrm{m})$ and small pores $(1.5-10 \mathrm{~nm})$, is interesting characteristic for progression of osteogenesis, mimicking the cancellous bone tissue. 



Fig. 1 - SEM micrographs show typical pore networks within $\beta$-TCP/BG scaffolds in different magnifications. Pure $\beta$-TCP (a) $50 \times$ and (b) $5000 \times$, and (c) 15,000 $; \beta$-TCP/5\%BG (d) $50 \times$ and (e) $5000 \times$, and (f) $15,000 \times ; \beta-\mathrm{TCP} / 7.5 \% \mathrm{BG}$ (g) $50 \times$, (h) $5000 \times$, and (i) $15,000 \times$.

\subsection{X-ray microtomography}

The SEM images of the scaffolds have shown a significant porosity. However, X-ray microtomography images could provide further understand of the porosity and morphology in a tridimensional microscale. Reconstructed images were obtained from the $\beta$-TCP scaffolds and $\beta$-TCP scaffolds containing different amount of bioglass, as presented in Fig. 2. The color bar is proportional to the attenuation of the X-rays when passing through the sample: colors on the left side show lower attenuation than ones on the right side. The attenuation is influenced by changes in the sample such as thickness, density and electronic density (basically, the atom number of the involved species).

Comparing the images for the $\beta$-TCP and $\beta$-TCP/x-BG scaffolds, it is possible to observe a slight decrease in the attenuation on the $\beta$-TCP with $7.5 \%-B G$, as shown in the tridimensional images reconstruction in Fig. 2 (left). For this reason, 2D slices were obtained inside of each one of the scaffold samples, as presented in Fig. 2 (right). The analyzed materials present a microstructure highly porous and a decrease in the attenuation was observed in the scaffold with higher quantity of bioglass, as expected considering that the bioglass contains lighter elements ( $\mathrm{Si}$ and $\mathrm{Na}$ ) than pure $\beta$-TCP (P and Ca).

The average total porosity determined by microtomography is $(79.6 \pm 1.3) \%,(77.1 \pm 1.9) \%$ and $(76.8 \pm 0.4) \%$ for $\beta$-TCP, $\beta$ $\mathrm{TCP} / 5 \%-\mathrm{BG}$ and $\beta$-TCP/7.5\%-BG, respectively. The porosity is slight lower than the obtained by the geometrical porosity for all scaffolds, which is expected, considering that meso and nanopores can be also calculated by this method.

Fig. 3 presents the 3D model obtained from the Fig. 2 and their respective pore size distribution. All the samples show a wide pores size distribution, as observed in SEM images as well, and similar porosity, confirming that bioglass acts mainly as a binder for $\beta$-TCP grains.

\subsection{Structural characterization of $\beta$-TCP and $\beta-\mathrm{TCP} / x \%$ - BG scaffolds}

Fig. 4 shows XRD diffractograms for $\beta$-TCP and $\beta$-TCP/x\%-BG scaffolds sintered at $1200{ }^{\circ} \mathrm{C}$ for $2 \mathrm{~h}$.

The XRD diffractograms for $\beta$-TCP scaffolds (JCPDS 090169) confirm the presence of only $\beta$-TCP crystalline phase, whereas for $\beta$-TCP/x\%-BG scaffolds a second crystalline phase can be observed, $\alpha$-TCP (JCPDS 09-0348). $\beta$-TCP is the common polymorphic phase found for tricalcium phosphate thermal 

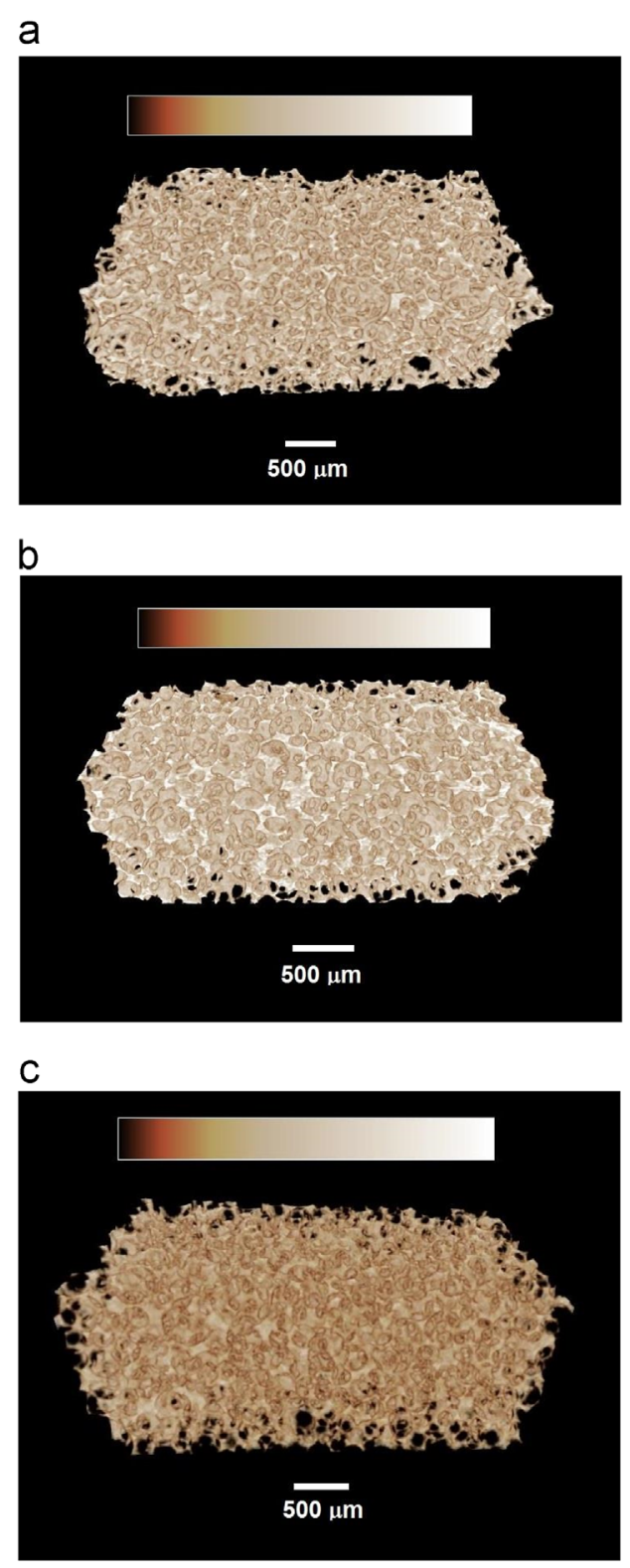
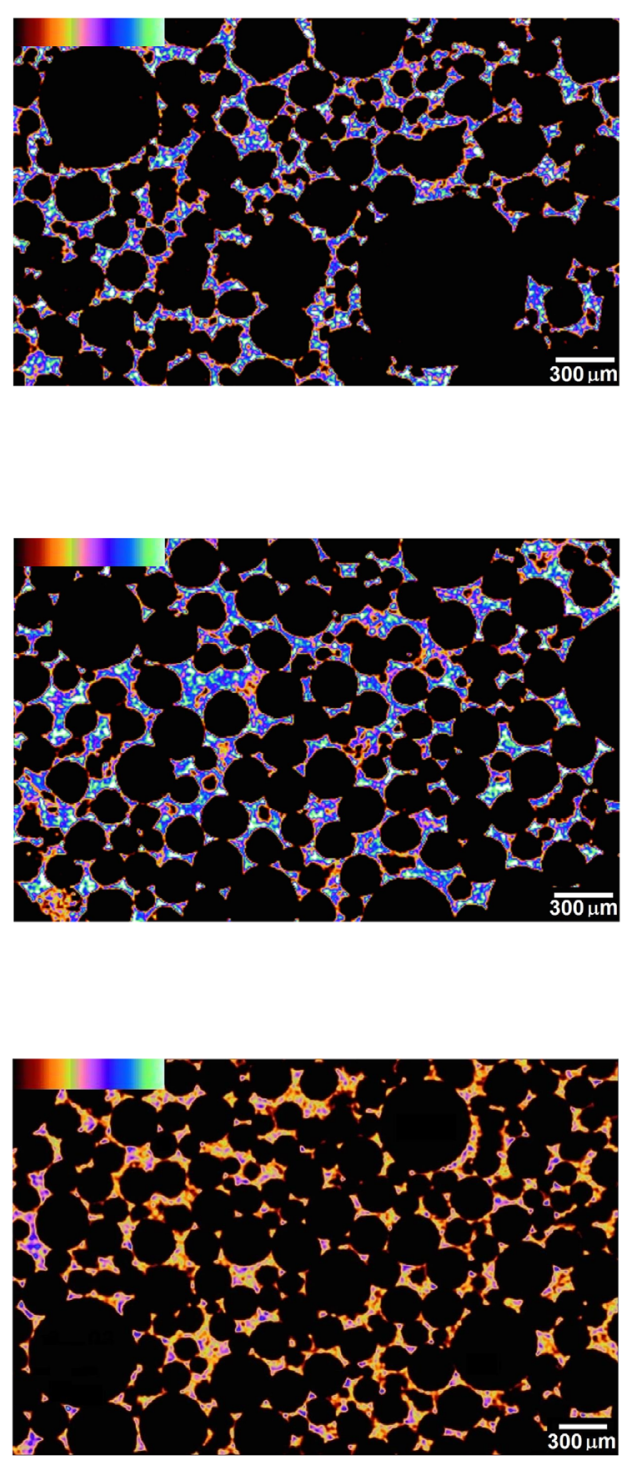

Fig. 2 - X-ray microtomography images: (a) $\beta$-TCP; (b) $\beta$-TCP/5\%-BG and (c) $\beta$-TCP/7.5\%-BG. Left: 3D images. Right: $2 \mathrm{D}$ cross sections obtained from 3D images. (For interpretation of the references to color in this figure, the reader is referred to the web version of this article.)

treated at temperatures between 850 and $1300{ }^{\circ} \mathrm{C}$, depending on the ionic impurities found in the precursors powders (Motisuke et al., 2008; Carrodeguas and De Aza, 2011). The influence of ionic substitution, such as $\mathrm{Na}^{+}$(Matsumoto et al., 2009), $\mathrm{Mg}^{2+}$ (Carrodeguas et al., 2008; Enderle et al., 2005), $\mathrm{SiO}_{4}^{2-}$ (Motisuke et al., 2008; Reid et al., 2006), $\mathrm{Li}^{+}$(Matsumoto et al., 2009), on the thermal stability of $\alpha$ and $\beta$-TCP phases have been discussed on the literature for at least ten years. Moreover, it is also well reported that $\mathrm{Si}$ may reduce the thermal stability of $\beta$-TCP to lower temperatures enabling $\alpha$ TCP to form at temperatures lower than the usual/theoretical ones. In fact, various authors have observed an alteration of the transition temperature phase of $\beta$-TCP to $\alpha$-TCP by the addition of Si (Reid et al., 2005; Motisuke et al., 2008; Duncan et al., 2014; Pietak et al., 2007).
Considering that in this present work the scaffolds were sintered at $1200^{\circ} \mathrm{C}$, the formation of $\alpha$-TCP at lower temperature might be attributed to the silicon present in the bioglass. Based on this model, the silicon delivered from bioglass particles during scaffold prepare/sintering may act as "a catalyst" for the phase transition. Indeed, XRD patterns do not reveal the presence of any crystalline phase related to the bioglass, i.e., $\mathrm{Na}_{2} \mathrm{CaSi}_{2} \mathrm{O}_{6}$ (Lefebvre et al., 2007) or similar crystalline phase (Lin et al., 2005).

Aiming to address this issue short-range structure was investigated by Raman spectroscopy, which is one powerful tool to investigate crystalline and noncrystalline materials such as ceramics and glasses. In Fig. 5a, $\beta$-TCP spectrum shows well-defined Raman scattering bands between 930 and $980 \mathrm{~cm}^{-1}$, in the frequency region of the $\mathrm{PO}_{4}^{3-}$ symmetric stretching, two peaks, at 949 and $970 \mathrm{~cm}^{-1}$, and a shoulder, at 

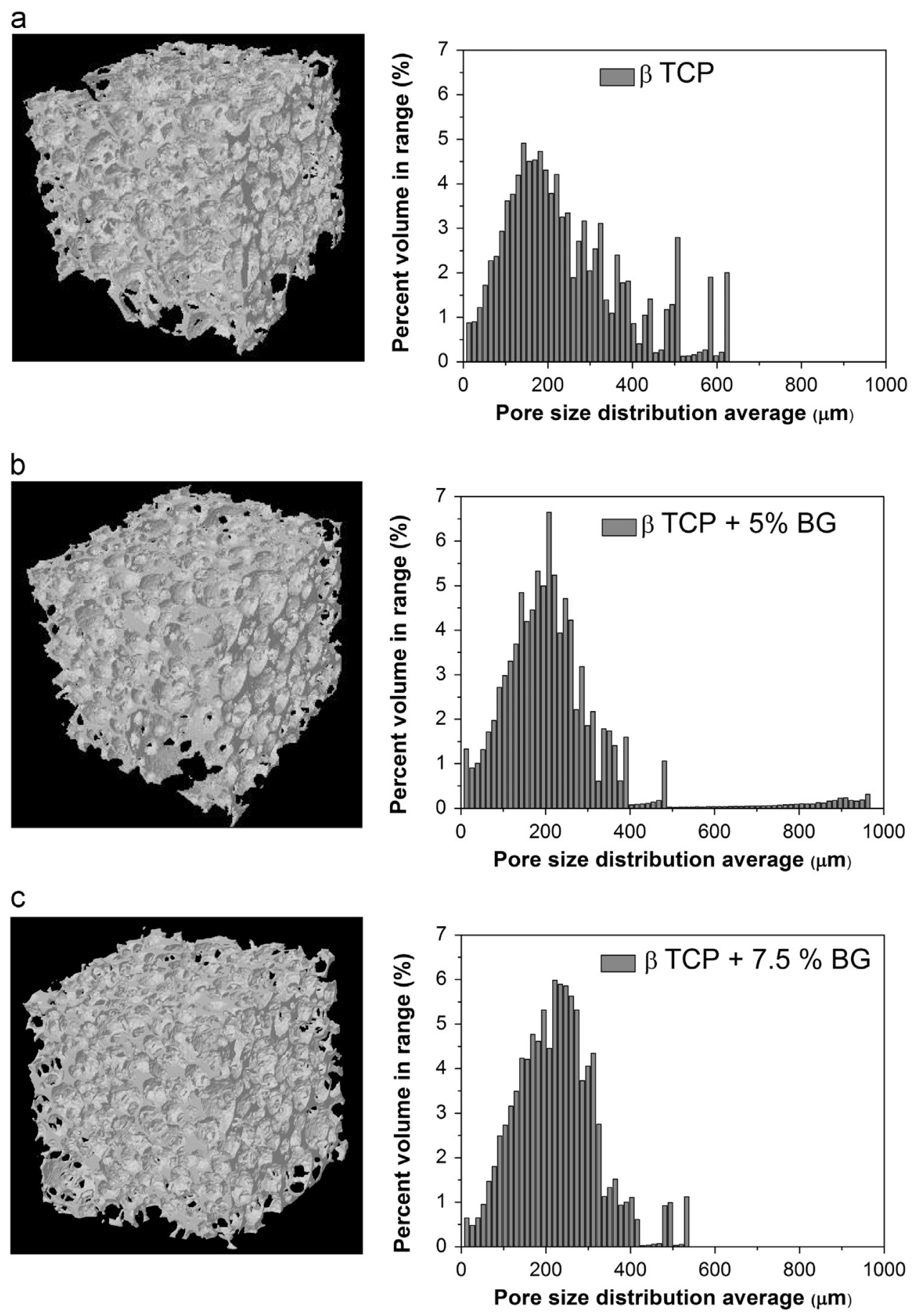

Fig. 3 - Left: 3D model reconstructed for the scaffold presented in Fig. 2. Right: pore size distribution average. (a) $\beta$-TCP; (b) $\beta$ TCP/5\%-BG and (c) $\beta$-TCP/7.5\%-BG. The scaffold volume of interest (VOI) used to create the 3D model was $8 \mathrm{~mm}^{3}$.

$960 \mathrm{~cm}^{-1}$ related to $\nu_{1}$ vibrational mode. Some spectral features are detected between 400 and $500 \mathrm{~cm}^{-1}$ where occur three broad peaks at 405,440 , and $480 \mathrm{~cm}^{-1}$ ascribed to $\nu_{2}$ $\mathrm{PO}_{4}^{3-}$ tetrahedron modes. In addition, very weak absorptions above $1000 \mathrm{~cm}^{-1}$ related to internal asymmetric stretching modes $\nu_{3}$ are observed at 1016 and $1090 \mathrm{~cm}^{-1}$. Raman peaks corresponding to $\nu_{4}$ bond-bending tetrahedron modes can be observed in the frequency region between 500 and $650 \mathrm{~cm}^{-1}$, where more distinct peaks manifest at 548 and $612 \mathrm{~cm}^{-1}$ (de Aza et al., 1997; Vani et al., 2009). Raman results tallies with the previous studies on $\beta$-TCP reported by other authors in the literature (de Aza et al., 1997; Li et al., 2004).

Raman spectra for $\beta-\mathrm{TCP} / \mathrm{x} \% \mathrm{BG}$ show some spectral changes at higher frequencies compared to pure $\beta$-TCP (Fig. 5b). As can be seen for $\beta$-TCP/x\%-BG the absorption in higher frequency named "complex band" from now on, splits into 951, 955, and $972 \mathrm{~cm}^{-1}$ (Fig. 5b) and the base spreads over a range from 930 to $980 \mathrm{~cm}^{-1}$. The complex band is quite sensitive to speciation of different crystalline phases of calcium phosphates and it is related to the overlapping of the various peaks that characterize the $\beta$-TCP $(934$, 
946, 949, 962, $\left.969 \mathrm{~cm}^{-1}\right)$ and $\alpha-\mathrm{TCP}\left(951,963,972,982 \mathrm{~cm}^{-1}\right)(\mathrm{Li}$ et al., 2004). Raman spectra for $45 \mathrm{~S} 5$ bioglass exhibit two broad and more intense absorptions at 630 and $945 \mathrm{~cm}^{-1}$ and two narrow peaks centered at 590 and $990 \mathrm{~cm}^{-1}$ for $45 S 5$ devitrified (see topic SM.3 - Fig. SM.3). By analyzing the Raman spectra of the $\beta$-TCP $/ \mathrm{x} \%-\mathrm{BG}$ scaffolds is not possible to identify any evidence of the presence of the absorptions related to $45 S 5$ bioglass, as well as to its corresponding devitrified. Thus, Raman results corroborate $\mathrm{XRD}$ data, indicating the absence of any band related to BG particles, indicating that silicon may have been incorporated in the crystal structure of TCP. This assumption is strengthened further by solid-state magic-angle spinning (Elliott, 1994) P MAS NMR spectroscopy studies (see topic SM.4 - Fig. SM.4).

In fact, it is well known that the silicon can substitute phosphorus sites into the $\beta$-TCP lattice inducing a phase transformation to Si-TCP, termed silicon stabilized tricalcium phosphate (Reid et al., 2005). Si-TCP has the same unit cell symmetry of $\alpha$-TCP, P2 $1 / a$, but different values of the lattice parameters are

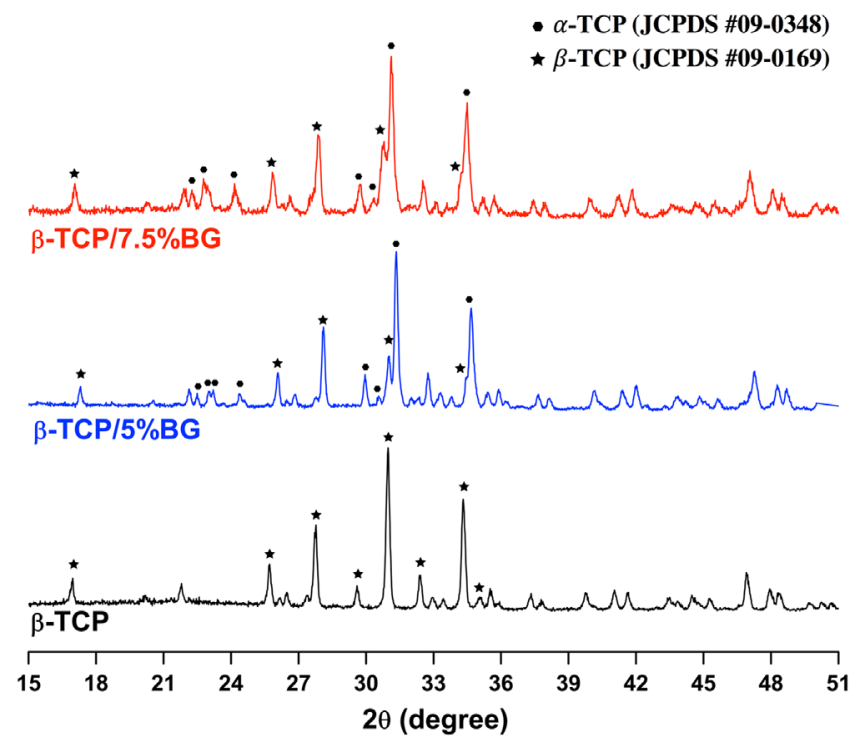

Fig. 4 - XRD diffractograms for $\beta$-TCP and $\beta$-TCP/x\%-BG scaffolds sintered at $1200{ }^{\circ} \mathrm{C}$ for $2 \mathrm{~h}$.

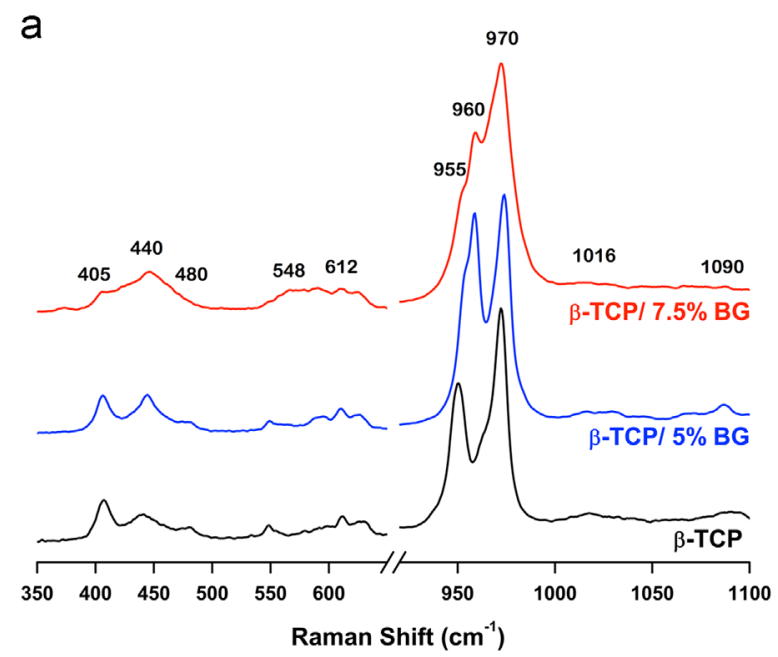

observed due to the substitution of silicon into tetrahedral phosphorus sites (Sayer et al., 2003). The phase transition has been described by a concomitant structural expansion, which was attributed to the lower density and higher cell volume of $\alpha$ TCP $\left(2.86 \mathrm{~g} \mathrm{~cm}^{-3}\right.$ and $\left.4317.52 \AA^{3}\right)$ compared to $\beta$-TCP $\left(3.07 \mathrm{~g} \mathrm{~cm}^{-3}\right.$ and 3527.26 $\AA^{3}$ ) (Hesaraki et al., 2009; Mathew et al., 1977). Thus, differentiation of the crystalline phases $\alpha$-TCP and Si-TCP, using $\mathrm{XRD}$ as well as Raman spectroscopy, is not an easy task due to the overlapping absorption bands.

Regarding to the mechanism of transformation $\beta$-TCP $\rightarrow \alpha$ $\mathrm{TCP}+\mathrm{Si}-\mathrm{TCP}$ in the $\beta$-TCP/x\%-BG samples, it can be inferred that the bioglass particles are partially dissolved during the manufacturing process of the scaffold. By considering that the gelcasting method was carried out in the presence of water, the remaining particles (of very small size) melt during calcination step, catalyzing the phase transformation. Thus ions and silica released ions of 4555 bioglass can absorb on the surface of the $\beta$ TCP grains and are incorporated into the crystalline structure, influencing its lattice parameters as well as atomic site occupancy (Qiu et al., 2013). This model supports the hypothesis that the addition of silica or silicon in the $\beta$-TCP provides a mechanism for the nucleation of a $\mathrm{Si} / \alpha$-TCP phase type at temperatures lower than those predicted by the conventional phase diagram (Reid et al., 2005; Pietak et al., 2007; Motisuke et al., 2012).

Concerning the effect of bioglass on the mechanical behavior exhibited by the $\beta$-TCP/x\%-BG scaffolds, two considerations should be made in order to build a model that corroborate the data obtained. The presence of sodium originating from the bioglass leads to a softening of the surface of the TCP granules at lower temperatures than usual, enhancing sintering and grain growth. Thus, the modified surface of the granules with the sodium ion released from bioglass dissolution acts as "glue" for particles leading to an increased mechanical strength.

In fact, X-ray mapping confirms that the sodium and silica are entirely distributed throughout $\beta$-TCP/X\%-BG scaffolds (Fig. 6).

On the other hand, as bioglass content increases occurs a progressive replacement of the phosphorus present in the lattice of TCP by silicon. This atomic replacement reaches a maximum value (about $5-7.5 \%$ in wt of $B G$ ) until saturation

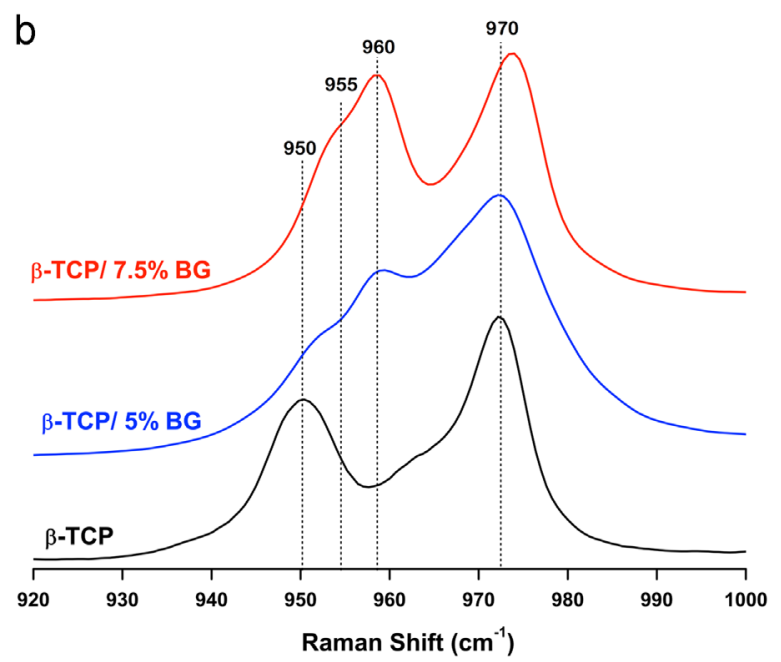

Fig. 5 - Raman spectra for $\beta$-TCP and $\beta$-TCP/x\%BG scaffolds: (a) full-range and (b) zoomed over a range from 920 to $1000 \mathrm{~cm}^{-1}$ of the Raman spectra. 

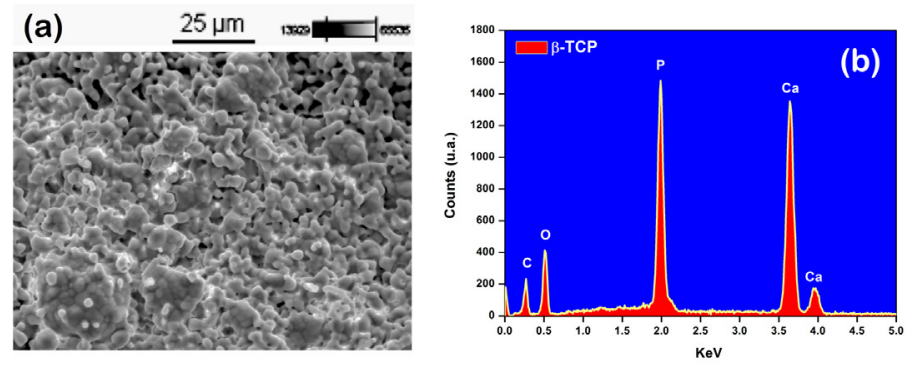

(c)

\begin{tabular}{|c|}
\hline Atom $\%$ \\
\hline $\mathrm{O}-60.38$ \\
\hline $\mathrm{P}-15.45$ \\
$\mathrm{Ca}-24.17$ \\
\hline
\end{tabular}
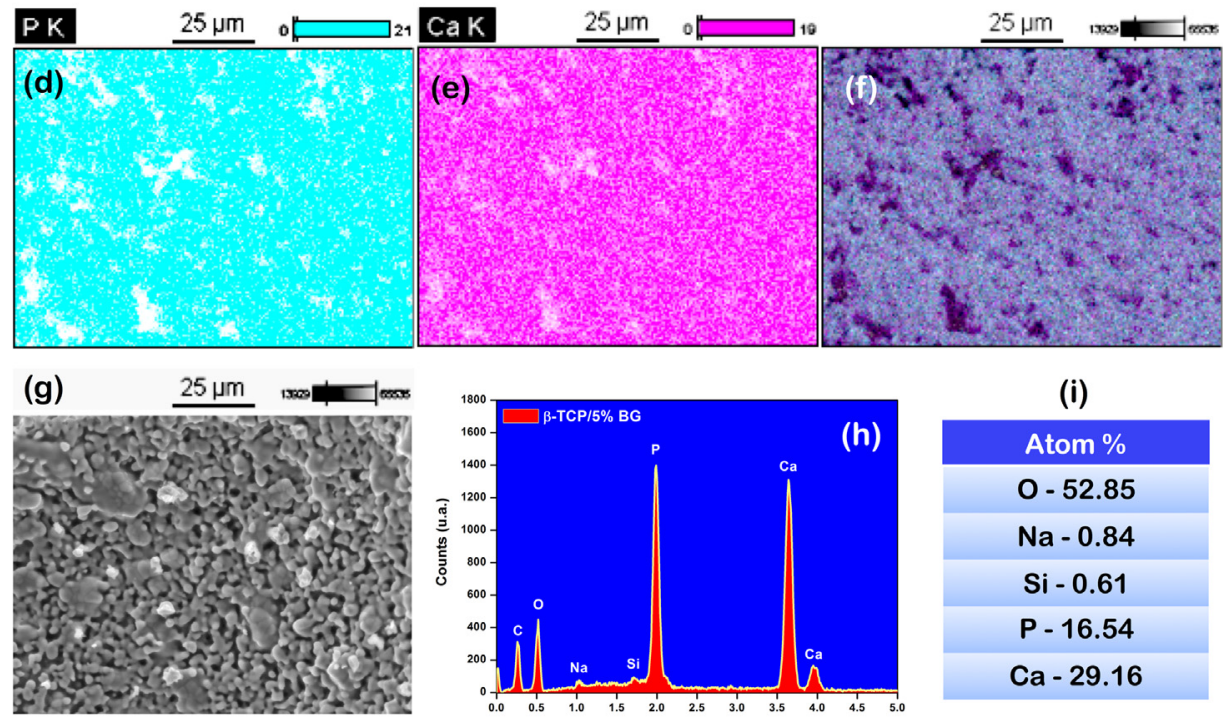

(i)
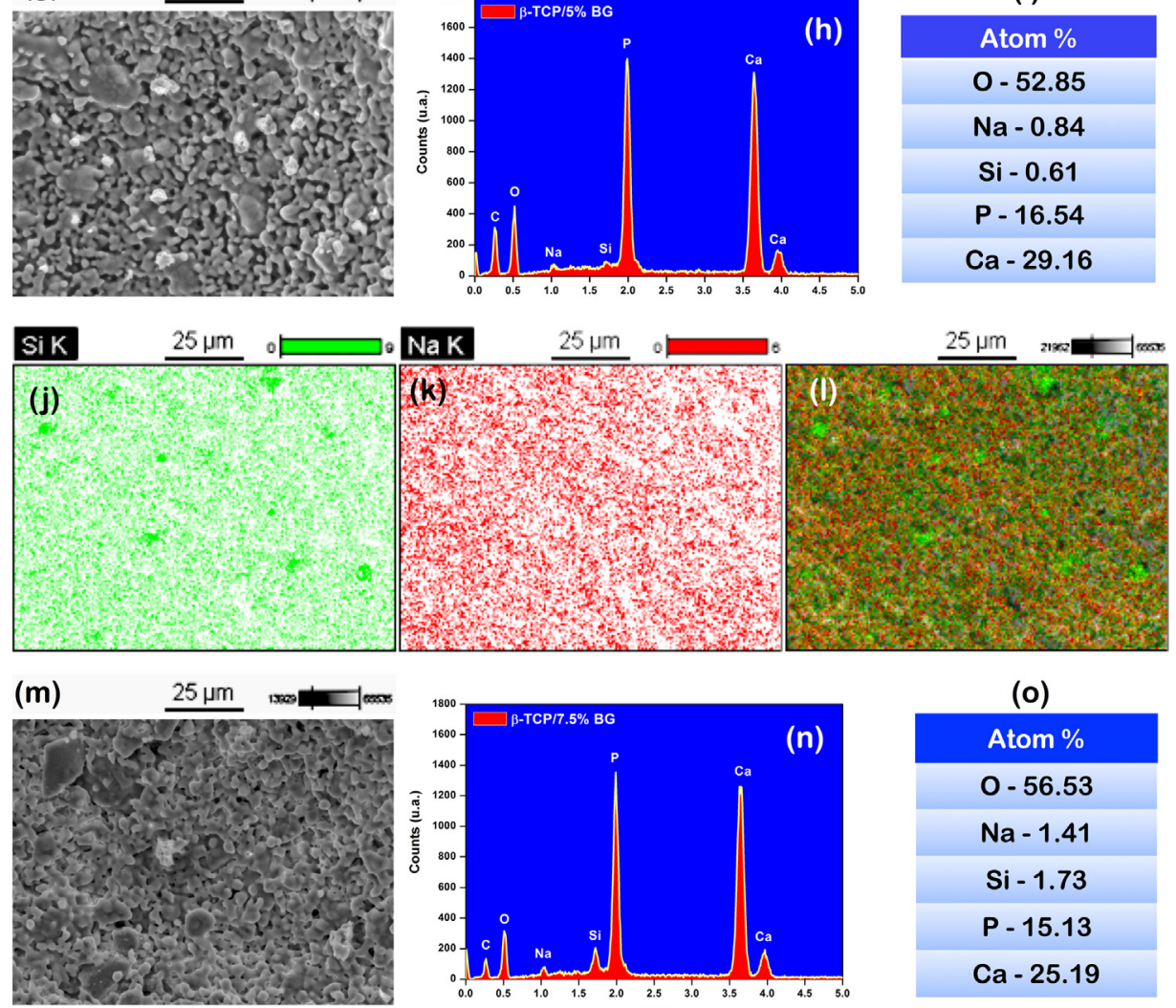

(o)
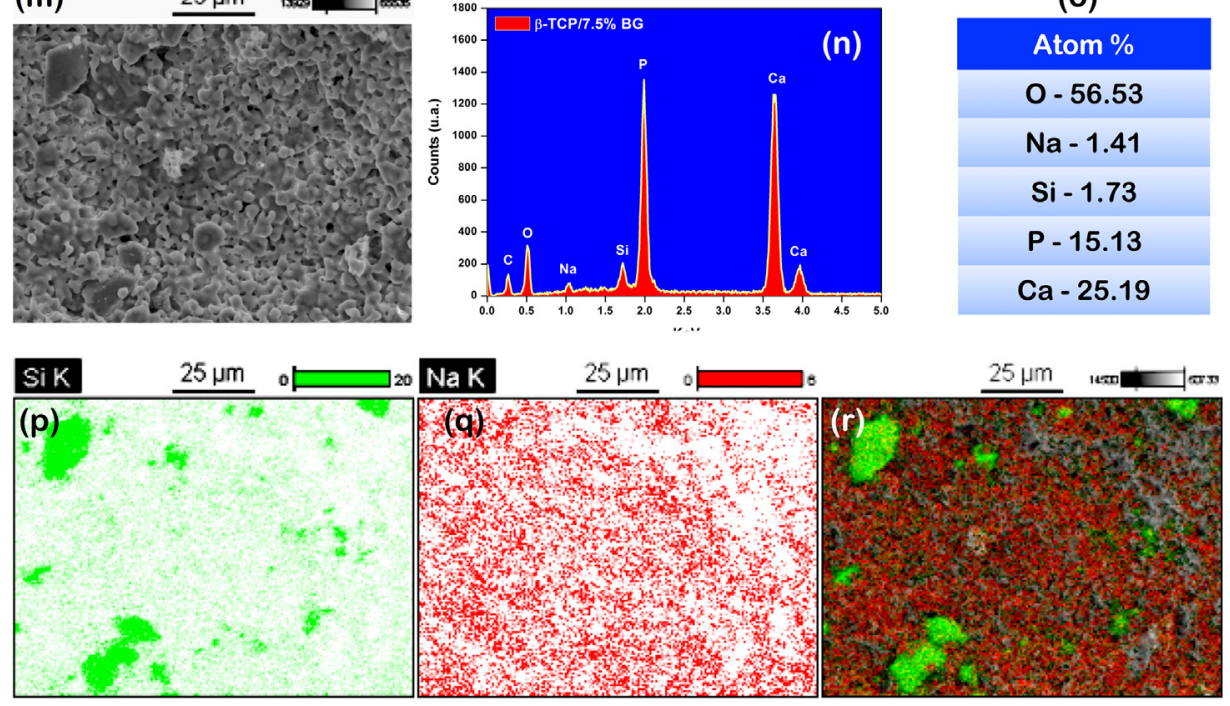

Fig. 6 - X-ray mapping for $\beta$-TCP and $\beta$-TCP/x\%BG scaffolds: (a) SEM picture showing the analyzed region in the $\beta$-TCP scaffold, (b) EDS spectra confirming qualitatively and (c) quantitatively the chemical composition of pure $\beta$-TCP. SEM spectral image for (d) calcium, (e) silicon, and (f) the X-ray mapping overlay of $\mathrm{Ca}$ and $\mathrm{P}$ signals. (g) SEM picture, (h) EDS spectrum, and (i) chemical composition of $\beta$-TCP/5\%BG scaffold. X-ray mapping displaying the $(j)$ silicon, (k) sodium distribution in the $\beta$-TCP/5\%BG sample, and (l) overlay of $\mathrm{Si}$ and Na signals. $(\mathrm{m})$ SEM picture showing the probed region, (n) EDS spectrum, and (o) elemental analysis for $\beta$-TCP/7.5\%BG scaffold. SEM spectral image for (p) silicon, (q) sodium, and ( $r$ ) the $\mathrm{X}$-ray mapping overlay of Si and Na signals showing the presence of silica clusters on the scaffolds. 
occurs, thereafter, any amount of silicon provided by bioglass remains excluded from the crystal lattice of the $\beta$-TCP. Excess of $\mathrm{Si}$ doping also takes negative effects on the sintering properties of $\beta$-TCP. Indeed, it has been demonstrated that densification temperature of Si-Calcium phosphates in the sintering was raised with the increase of Si content (Gibson et al., 2002).

Fig. 7 shows a possible scheme of the mechanism of events that occur during the fabrication of scaffolds by gelcasting method.

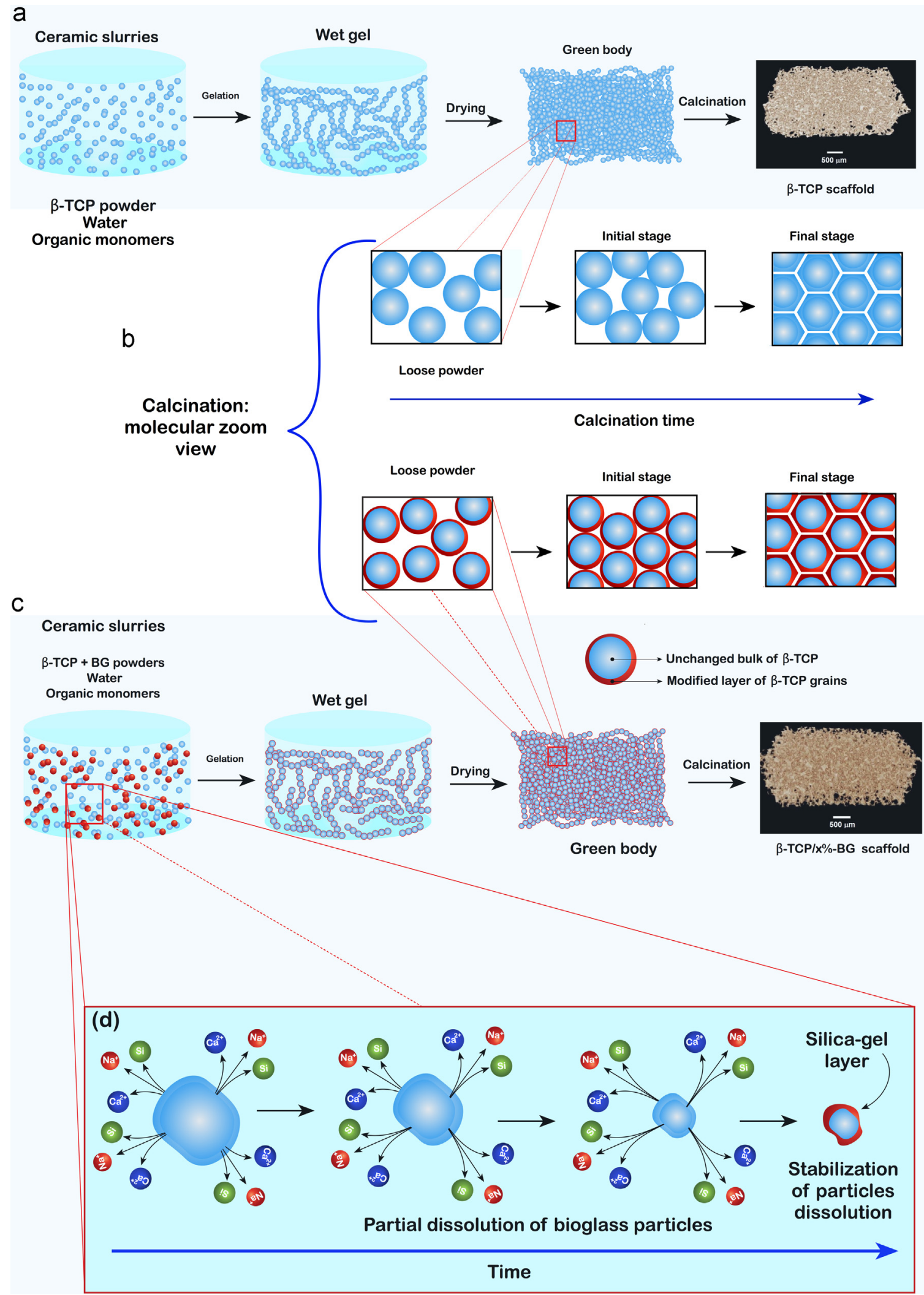

Fig. 7 - Scheme of the fabrication of scaffolds by gel-casting method. (a) Scaffold of pure $\beta$-TCP. (b) Molecular approach of the mechanism related to events that occur during the calcination. (c) Prepare of $\beta$-TCP/X\%-BG scaffolds. (d) Bioglass particles behavior in aqueous solution, as proposed by Hench's mechanism. 


\subsection{Proliferation and cell viability of scaffolds}

Statistical analysis of the data obtained in the MTT test showed that none of the tested materials was cytotoxic. The $\beta$-TCP, $\beta$-TCP-5BG and $\beta$-TCP-7.5BG tested in this study showed values of absorbance statistically different from the control group $(P<0.05)$. Fig. 8 shows a statistically similar decreasing of cell viability for $\beta$-TCP (68.4\%) and $\beta$-TCP-5BG (64.5\%) samples, whereas for the $\beta$-TCP-7.5BG scaffold, the higher amount of bioglass leads to the increased cell viability (132.4\%), which was statistically different from the other ones $(P<0.05)$.

The citotoxicity assay measured the viability of the cell, after contact with the samples, through the MTT test. This assay shows not only the number of cells, but also the level of its metabolic activity because it is based on the activity of enzymes, such as succicil dehydrogenase, which is present in viable cells. In the present study, it was observed that $\beta$-TCP and $\beta$-TCP-5BG decreased the number of viable cells. However, these materials were not cytotoxic. On the other hand, the $\beta$-TCP-7.5BG promoted a high cell proliferation. Thus, it was observed that the higher concentration of BG, the higher the number of viable cells.

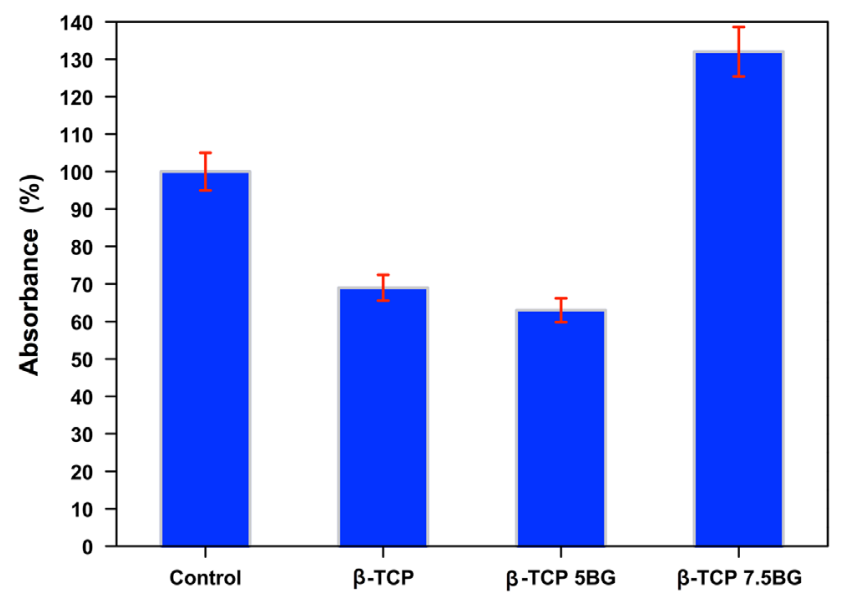

Fig. 8 - Graph showing the mean percentage of absorbance, obtained with MTT assay, of $\beta$-TCP, $\beta$-TCP-5BG and $\beta$-TCP7.5BG and control group (100\%) after $24 \mathrm{~h}$ in contact with MG 63 cells.
Cell attachment is presumably the most important stage of the cell interaction with a biomaterial because it is needed for other cellular activities, such as spreading, proliferation and biosynthesis (Khalili and Ahmad, 2015). In our study, it was observed that the cells were able to adhere and spread on the surface of all materials, suggesting an excellent interaction between cells and scaffolds. (Fig. 9).

Furthermore, it was observed that cells present on the $\beta$ $\mathrm{TCP} / \mathrm{x} \%-\mathrm{BG}$ were partially immersed in the material bulk and some cytoplasmic extensions entered into the scaffolds pores. A similar behavior has been reported in the literature for osteoblast-like cell in silicate-based cements (Gandolfi et al., 2008).

\section{Conclusion}

In this study, composites of $\beta$-TCP ( $\beta$-Tricalcium Phosphate) and $45 \mathrm{~S} 5$ bioactive glass have been fabricated by gel-casting. The scaffolds presented a homogeneous macrostructure with spherical and interconnected pores and mean pore size varied in the range of $200-500 \mu \mathrm{m}$. The structural investigation of scaffolds by XRD, Raman and (Elliott, 1994) P MAS NMR spectroscopies revealed that the ionic product originated from $45 \mathrm{~S} 5$ induces a phase transition from $\beta$-TCP to Si-TCP by replacement of phosphorus for silicon in the lattice. $\beta$-TCP/ $5 \%-B G$ and $\beta$-TCP/7.5\%-BG scaffolds showed a similar mechanical strength to the trabecular bone, exhibiting values for the compressive strength approximately twice as high as compared to pure TCP. The ability of $\beta$-TCP/5\%-BG composites to support the growth of human osteoblastic cells showed that none of the tested materials was cytotoxic. It was concluded that $\beta$-TCP as well as $\beta$-TCP-5BG and $\beta$-TCP-7.5BG were biocompatible. However, $\beta$-TCP-7.5BG was the better material since it has increased the cell proliferation more than control group.

Our findings suggest that the introduction of $45 \mathrm{~S} 5$ bioglass into porous $\beta$-TCP bioceramics may be an effective approach to prepare bioactive scaffolds for bone tissue engineering applications, and to control properties such as degradability and osteoinduction of $\beta$-TCP.
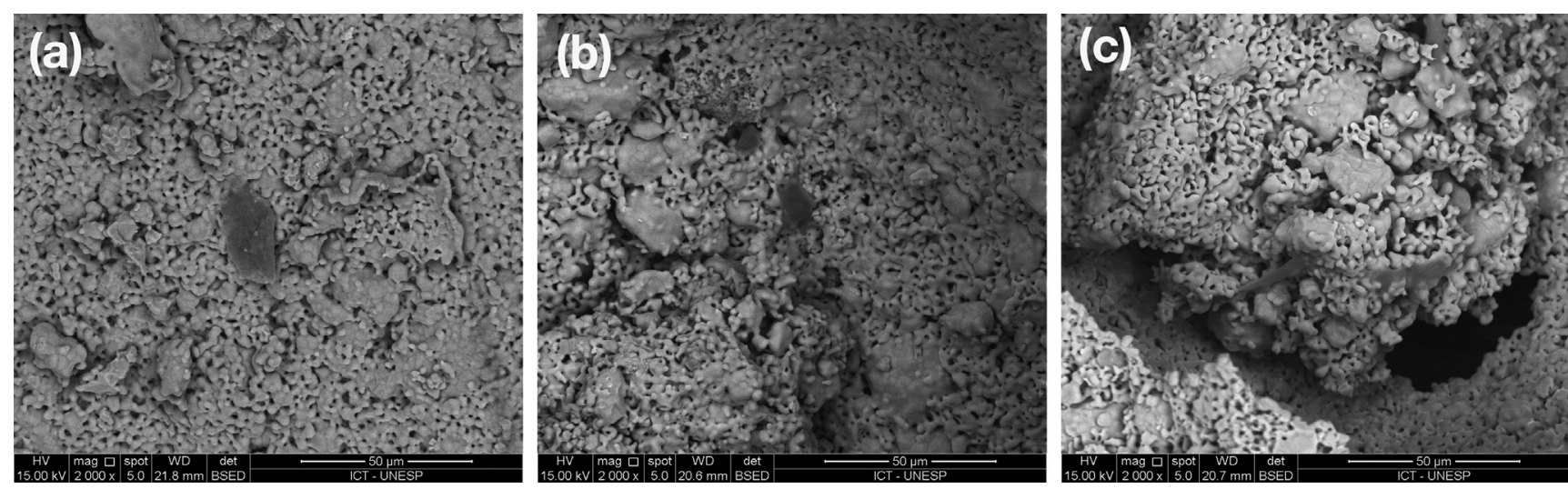

Fig. 9 - Representative images of adhered cells on $\beta$-TCP, (a) $\beta$-TCP-5BG and (b) $\beta$-TCP-7.5BG (c) after 3 days. 


\section{Acknowledgments}

The authors acknowledge the use of the analytical instrumentation facility at Institute of Chemistry - University of Campinas, which is supported by the State of Paulo, and LNNano for X-ray microtomography images. This work was carried out with the support of the São Paulo Research Foundation - FAPESP (Grant: 2010/12376-5, 2010/00863-0, 2011/09240-9 and 2011/17877-7) and The National Council for Scientific and Technological Development (CNPq/PIBITI, Grant: 456461/2014-0).

\section{Appendix A. Supplementary material}

Supplementary data associated with this article can be found in the online version at http://dx.doi.org/10.1016/j.jmbbm. 2016.04.028.

\section{R E F E R E N C E S}

de Aza, P.N., Santos, C., Pazo, A., de Aza, S., Cuscó, R., Artús, L., 1997. Vibrational properties of calcium phosphate compounds. 1. raman spectrum of $\beta$-tricalcium phosphate. Chem. Mater. 9 (4), 912-915.

Baino, F., Vitale-Brovarone, C., 2011. Three-dimensional glassderived scaffolds for bone tissue engineering: current trends and forecasts for the future. J. Biomed. Mater. Res. Part A 97A (4), 514-535.

Black, J., Hastings, G., 1998. Handbook of Biomaterial Properties. Springer, US.

Carrodeguas, R.G., De Aza, S., 2011. Alpha-tricalcium phosphate: synthesis, properties and biomedical applications. Acta Biomater. 7 (10), 3536-3546.

Carrodeguas, R.G., De Aza, A.H., Turrillas, X., Pena, P., De Aza, S., 2008. New approach to the beta-alpha polymorphic transformation in magnesium-substituted tricalcium phosphate and its practical implications. J. Am. Ceram. Soc. 91 (4), 1281-1286.

Chopra, K., Mummery, P.M., Derby, B., Gough, J.E., 2012. Gel-cast glass-ceramic tissue scaffolds of controlled architecture produced via stereolithography of moulds. Biofabrication 4 (4), 045002.

Debusscher, F., Aunoble, S., Alsawad, Y., Clement, D., Le Huec, J.-C., 2009. Anterior cervical fusion with a bio-resorbable composite cage (beta TCP-PLLA): clinical and radiological results from a prospective study on 20 patients. Eur. Spine J. 18 (9), 1314-1320.

Deville, S., Saiz, E., Tomsia, A.P., 2006. Freeze casting of hydroxyapatite scaffolds for bone tissue engineering. Biomaterials 27 (32), 5480-5489.

Duncan, J., Hayakawa, S., Osaka, A., MacDonald, J.F., Hanna, J.V., Skakle, J.M.S., Gibson, I.R., 2014. Furthering the understanding of silicate-substitution in a-tricalcium phosphate: an X-ray diffraction, X-ray fluorescence and solid-state nuclear magnetic resonance study. Acta Biomater. 10 (3), 1443-1450.

Elliott, J.C., 1994. Studies in Inorganic Chemistry: Structure and Chemistry of the Apatites and Other Calcium Orthophosphates. Vol. 18. Elsevier Science, The Netherlands 1-62.

Enderle, R., Götz-Neunhoeffer, F., Göbbels, M., Müller, F.A., Greil, P., 2005. Influence of magnesium doping on the phase transformation temperature of $\beta$-TCP ceramics examined by Rietveld refinement. Biomaterials 26 (17), 3379-3384.
Fisher, M.B., Mauck, R.L., 2013. Tissue engineering and regenerative medicine: recent innovations and the transition to translation. Tissue Eng. Part B: Rev. 19 (1), 1-13.

Gandolfi, M.G., Pagani, S., Perut, F., Ciapetti, G., Baldini, N., Mongiorgi, R., Prati, C., 2008. Innovative silicate-based cements for endodontics: a study of osteoblast-like cell response. J. Biomed. Mater. Res. Part A 87A (2), 477-486.

Gerhardt, L.C., Boccaccini, A.R., 2010. Bioactive glass and glassceramic scaffolds for bone tissue engineering. Materials 3 (7), 3867-3910.

Gibson, I.R., Best, S.M., Bonfield, W., 2002. Effect of silicon substitution on the sintering and microstructure of hydroxyapatite. J. Am. Ceram. Soc. 85 (11), 2771-2777.

Hench, L.L., Wilson, J., 1999. An Introduction to Bioceramics. World Scientific, Singapore [u.a.]386.

Hesaraki, S., Safari, M., Shokrgozar, M.A., 2009. Development of $\beta$ tricalcium phosphate/sol-gel derived bioactive glass composites: physical, mechanical, and in vitro biological evaluations. J. Biomed. Mater. Res. Part B: Appl. Biomater. 91B (1), 459-469.

Jones, J.R., Hench, L.L., 2003. Regeneration of trabecular bone using porous ceramics. Curr. Opin. Solid State Mater. Sci. 7 (4-5), 301-307.

Jones, J.R., Hench, L.L., 2003b. Effect of porosity on the mechanical properties of bioactive foam scaffolds. In: BenNissan, B., Sher, D., Walsh, W. (Eds.), Bioceramics. 15, pp. 209-212.

Khalili, A., Ahmad, M., 2015. A review of cell adhesion studies for biomedical and biological applications. Int. J. Mol. Sci. 16 (8), 18149.

Kim, Z.-K., Oak, J.-J., Kimura, H., Goto, T., Inoue, A., Yoon, S.-Y., 2009. Achitecture of porous hydroxyapatite scaffolds using polymer foam process. J. Biomech. Sci. Eng. 4 (3), 377-383.

Langstaff, S., Sayer, M., Smith, T.J.N., Pugh, S.M., 2001. Resorbable bioceramics based on stabilized calcium phosphates. Part II: evaluation of biological response. Biomaterials 22 (2), 135-150.

Lefebvre, L., Chevalier, J., Gremillard, L., Zenati, R., Thollet, G., Bernache-Assolant, D., Govin, A., 2007. Structural transformations of bioactive glass $45 \mathrm{~S} 5$ with thermal treatments. Acta Mater. 55 (10), 3305-3313.

Li, H., Ng, B.S., Khor, K.A., Cheang, P., Clyne, T.W., 2004. Raman spectroscopy determination of phases within thermal sprayed hydroxyapatite splats and subsequent in vitro dissolution examination. Acta Mater. 52 (2), 445-453.

Li, X., Bian, W., Li, D., Lian, Q., Jin, Z., 2011. Fabrication of porous beta-tricalcium phosphate with microchannel and customized geometry based on gel-casting and rapid prototyping. Proc. Inst. Mech. Eng. Part H: J. Eng. Med. 225 (H3), 315-323.

Liang, L., Rulis, P., Ching, W.Y., 2010. Mechanical properties, electronic structure and bonding of $\alpha$ - and $\beta$-tricalcium phosphates with surface characterization. Acta Biomater. 6 (9), 3763-3771.

Lin, C.C., Huang, L.C., Shen, P.Y., 2005. $\mathrm{Na}_{2} \mathrm{CaSi}_{2} \mathrm{O}_{6}-\mathrm{P}_{2} \mathrm{O}_{5}$ based bioactive glasses. Part 1: elasticity and structure. J. Non-Cryst. Solids 351 (40-42), 3195-3203.

Lin, L., Ju, S., Cen, L., Zhang, H., Hu, Q., 2008. Fabrication of porous $\beta$-TCP scaffolds by combination of rapid prototyping and freeze drying technology. In: Peng, Y., Weng, X. (Eds.), 7th Asian-Pacific Conference on Medical and Biological Engineering. Springer Berlin, Heidelberg, pp. 88-91.

Lopes, J.H., Mazali, I.O., Landers, R., Bertran, C.A., 2013. Structural investigation of the surface of bioglass $45 \mathrm{~s} 5$ enriched with calcium ions. J. Am. Ceram. Soc. 96 (5), 1464-1469.

Lopes, J.H., Magalhaes, A., Mazali, I.O., Bertran, C.A., 2014. Effect of niobium oxide on the structure and properties of meltderived bioactive glasses. J. Am. Ceram. Soc. 97 (12), 3843-3852.

Mathew, M., Schroeder, L.W., Dickens, B., Brown, W.E., 1977. Crystal-structure of alpha- $\mathrm{Ca}_{3}\left(\mathrm{Po}_{4}\right)$ 2. Acta Crystallogr. Sect. BStruct. Sci. 33, 1325-1333. 
Matsumoto, N., Yoshida, K., Hashimoto, K., Toda, Y., 2009. Thermal stability of $\beta$-tricalcium phosphate doped with monovalent metal ions. Mater. Res. Bull. 44 (9), 1889-1894.

Motisuke, M., Carrodeguas, R.G., Zavaglia, C.A.D., 2012. Si-TCP synthesized from "Mg-free" reagents employed as calcium phosphate cement. Mater. Res. Ibero Am. J. Mater. 15 (4), 568-572.

Motisuke, M., Carrodeguas, R.G., Zavaglia, C.A.C., 2008. Mg-free precursors for the synthesis of pure phase Si-doped alpha-Ca3(PO4)(2). In: Daculsi, G., Layrolle, P., (Eds.), Bioceramics. 20, pp. 199-202.

Naderi, H., Matin, M.M., Bahrami, A.R., 2011. Review paper: critical issues in tissue engineering: biomaterials, cell sources, angiogenesis, and drug delivery systems. J. Biomater. Appl. 26 (4), 383-417.

Oliveira, A.P., Motisuke, M., Leal, C.V., Beppu, M.M., 2008. A comparative study between beta-TCP prepared by solid state reaction and by aqueous solution precipitation: application in cements. In: Daculsi, G., Layrolle, P. (Eds.), Bioceramics, 20. Trans Tech Publications Ltd, Stafa-Zurich, pp. 355-358.

Ortega, F.S., Valenzuela, F.A.O., Pandolfelli, V.C., 2003. Gelcasting ceramic foams with alternative gelling agents. Adv. Powder Technol. III 416-4, 512-518.

Pietak, A.M., Reid, J.W., Stott, M.J., Sayer, M., 2007. Silicon substitution in the calcium phosphate bioceramics. Biomaterials 28 (28), 4023-4032.

Qiu, Z.-Y., Noh, I.-S., Zhang, S.-M., 2013. Silicate-doped hydroxyapatite and its promotive effect on bone mineralization. Front. Mater. Sci. 7 (1), 40-50.

Reid, J.W., Pietak, A., Sayer, M., Dunfield, D., Smith, T.J.N., 2005. Phase formation and evolution in the silicon substituted tricalcium phosphate/apatite system. Biomaterials 26 (16), 2887-2897.

Reid, J.W., Tuck, L., Sayer, M., Fargo, K., Hendry, J.A., 2006. Synthesis and characterization of single-phase silicon-substituted $\alpha$-tricalcium phosphate. Biomaterials 27 (15), 2916-2925.

Reno, Cd.O., Pereta, N.C., Bertran, C.A., Motisuke, M., de Sousa, E., 2014. Study of in vitro degradation of brushite cements scaffolds. J. Mater.: Sci. Mater. Med. 25 (10), 2297-2303.

Salih, V., Georgiou, G., Knowles, J.C., Olsen, I., 2001. Glass reinforced hydroxyapatite for hard tissue surgery—Part II: in vitro evaluation of bone cell growth and function. Biomaterials 22 (20), 2817-2824.

Sayer, M., Stratilatov, A.D., Reid, J., Calderin, L., Stott, M.J., Yin, X., MacKenzie, M., Smith, T.J.N., Hendry, J.A., Langstaff, S.D., 2003. Structure and composition of silicon-stabilized tricalcium phosphate. Biomaterials 24 (3), 369-382.
Schwartz, M.M., 2003. Brazing, 2nd ASM International, OH, United States.

Sepulveda, P., Ortega, F.S., Innocentini, M.D.M., Pandolfelli, V.C., 2000. Properties of highly porous hydroxyapatite obtained by the gelcasting of foams. J. Am. Ceram. Soc. 83 (12), 3021-3024.

Serra, I.R., Fradique, R., Vallejo, M.C.S., Correia, T.R., Miguel, S.P., Correia, I.J., 2015. Production and characterization of chitosan/ gelatinip/beta-TCP scaffolds for improved bone tissue regeneration. Mater. Sci. Eng. C: Mater. Biol. Appl. 55, 592-604.

Shavandi, A., Bekhit, A.E.-D.A., Ali, M.A., Sun, Z., Gould, M., 2015. Development and characterization of hydroxyapatite/beta$\mathrm{TCP} /$ chitosan composites for tissue engineering applications. Mater. Sci. Eng. C: Mater. Biol. Appl. 56, 481-493.

Shuai, C., Yang, B., Peng, S., Min, A., 2014. Improved mechanical properties of beta-tricalcium phosphate by addition of akermanite and $45 \mathrm{~S} 5$ bioglass. Mater. Res. Innov. 18 (S2), S2-69-S273.

Vani, R., Girija, E.K., Elayaraja, K., Parthiban, S.P., Kesavamoorthy, R., Kalkura, S.N., 2009. Hydrothermal synthesis of porous triphasic hydroxyapatite/(alpha and beta) tricalcium phosphate. J. Mater. Sci.: Mater. Med. 20, 43-48.

Wu, Z.Y., Hill, R.G., Yue, S., Nightingale, D., Lee, P.D., Jones, J.R., 2011. Melt-derived bioactive glass scaffolds produced by a gelcast foaming technique. Acta Biomater. 7 (4), 1807-1816.

Xu, H.H.K., Burguera, E.F., Carey, L.E., 2007. Strong, macroporous, and in situ-setting calcium phosphate cement-layered structures. Biomaterials 28 (26), 3786-3796.

Xu, H.H.K., Quinn, J.B., Takagi, S., Chow, L.C., Eichmiller, F.C., 2001 Strong and macroporous calcium phosphate cement: effects of porosity and fiber reinforcement on mechanical properties. J. Biomed. Mater. Res. 57 (3), 457-466.

Yang, K., Zhang, J., Ma, X., Ma, Y., Kan, C., Ma, H., Li, Y., Yuan, Y., Liu, C., 2015. beta-Tricalcium phosphate/poly(glycerol sebacate) scaffolds with robust mechanical property for bone tissue engineering. Mater. Sci. Eng. C: Mater. Biol. Appl. 56, $37-47$.

Yang, T., Lee, J., Yoon, S., Park, H., 2010. Hydroxyapatite scaffolds processed using a TBA-based freeze-gel casting/polymer sponge technique. J. Mater. Sci.: Mater. Med. 21 (5), 1495-1502.

Yang, T.Y., Lee, J.M., Yoon, S.Y., Park, H.C., 2010. Hydroxyapatite scaffolds processed using a TBA-based freeze-gel casting/ polymer sponge technique. J. Mater. Sci.: Mater. Med. 21 (5), 1495-1502.

Zhang, D., Jain, H., Hupa, M., Hupa, L., 2012. In-vitro degradation and bioactivity of tailored amorphous multi porous scaffold structure. J. Am. Ceram. Soc. 95 (9), 2687-2694. 